\title{
Low dose budesonide improved asthma control in mild asthma; adding formoterol improved control in corticosteroid treated patients
}

O'Byrne PM, Barnes PJ, Rodriguez-Roisin R, et al. Low dose inhaled budesonide and formoterol in mild persistent asthma: the OPTIMA randomized trial. Am J Respir Crit Care Med 2001 Oct 15;164:1392-7.

QUESTION: In patients with mild asthma, do regular low doses of inhaled budesonide, with or without low doses of inhaled formoterol, reduce severe exacerbations and improve asthma control?

Design

Randomised \{allocation concealed*\}†, blinded \{patients, clinicians, data collectors, outcome assessors, data analysts, and monitoring committee $\} \uparrow, *$ placebo controlled trial with 1 year of follow up.

Setting

198 centres in 17 countries.

\section{Patients}

1970 patients who were $\geqslant 12$ years of age and had mild asthma. 698 corticosteroid free patients (group A) (mean age $31 \mathrm{y}, 60 \%$ women) had not used an inhaled corticosteroid for $\geqslant 3$ months and had an $\mathrm{FEV}_{1} \geqslant 80 \%$ of predicted normal after inhaling terbutaline, $1 \mathrm{mg}$. 1272 corticosteroid treated patients (group B) (mean age $37 \mathrm{y}$, $57 \%$ women) were receiving $\leqslant 400 \mu \mathrm{g} /$ day of inhaled budesonide or the equivalent for $\geqslant 3$ months, with an $\mathrm{FEV}_{1} \geqslant 70 \%$ of predicted normal after terbutaline. Data from 1947 patients (99\%) were included in the analysis.

\section{Intervention}

During a 4 week run-in period, group A patients received placebo and group B patients received budesonide, $100 \mu \mathrm{g}$ twice daily. Patients were then allocated to

\section{COMMENTARY}

Patients diagnosed with mild asthma and their physicians may underestimate the morbidity associated with this condition. Such morbidity can be appreciable and can include severe exacerbations, ${ }^{1}$ despite normal lung function results on "good" days. In the trial by O'Byrne $e t$ al, patients classified as having mild asthma had a mean baseline $\mathrm{FEV}_{1}$ $>85 \%$ of predicted normal. However, a third of patients in the placebo group (who did not receive inhaled corticosteroids) had severe exacerbations (with $>70 \%$ needing oral corticosteroids) and $47 \%$ had nocturnal awakenings; therefore, interventions to reduce the effects of these exacerbations are important.

Patients not previously receiving inhaled corticosteroids had a substantial benefit with $100 \mu \mathrm{g}$ of budesonide twice each day. Lung function improved, but adding formoterol conferred no further symptomatic benefit.

In patients who were already treated with inhaled corticosteroids, adding formoterol was more effective at preventing exacerbations than was doubling the dose of budesonide; this finding may be related to a flattening of the dose-response relation for inhaled corticosteroids in patients with mild asthma.

The effects of these medications on underlying disease processes are still unknown, which means that the long term effects on airway remodelling and airway inflammation cannot be predicted. ${ }^{2}$ However, on the basis of the current evidence, an appropriate management strategy for patients with mild asthma would be initial treatment with inhaled corticosteroids and the addition of long acting $\beta$-agonists if control subsequently worsens rather than increasing the dose of inhaled corticosteroids. Combination treatment also reduces the potential for long term side effects of higher dose monotherapy, which is contributing to expanding interest in compliance friendly combination inhaler devices.

Dion Grosser, MBBS

Brian Smith, MBBS

Queen Elizabeth Hospital Woodville, South Australia, Australia

1 Robertson CF, Rubinfeld AR, Bowes G. Pediatric asthma deaths in Victoria: the mild are at risk. Paediatr Pulmonol 1992;13:95-100.

2 Kips JC. Treating asthma, or is simply too simple? Am J Resp Crit Care Med 2001; $164 ; 1336-8$

twice daily treatment for 1 year. Group A patients were allocated to budesonide, $100 \mu \mathrm{g}(\mathrm{n}=228)$; budesonide, $100 \mu \mathrm{g}$, plus formoterol, $4.5 \mu \mathrm{g}(\mathrm{n}=231)$; or placebo $(\mathrm{n}=239)$. Group $\mathrm{B}$ patients were allocated to budesonide, $100 \mu \mathrm{g}(\mathrm{n}=322)$; budesonide $100 \mu \mathrm{g}$, plus formoterol, $4.5 \mu \mathrm{g}(\mathrm{n}=323)$; budesonide, $200 \mu \mathrm{g}(\mathrm{n}=312)$; or budesonide, $200 \mu \mathrm{g}$, plus formoterol, $4.5 \mu \mathrm{g}(\mathrm{n}=315)$. All doses were delivered by Bricanyl Turbuhaler (AstraZeneca, Lund, Sweden), and stated doses were metered doses for budesonide and delivered doses for formoterol.

\section{Main outcome measures}

Main outcomes were time to first severe asthma exacerbation (need for treatment with oral corticosteroids, hospital admission or emergency treatment for worsening asthma, or a decrease in morning peak expiratory flow rate $[\mathrm{PEFR}]>25 \%$ from baseline on 2 consecutive d) and poorly controlled asthma days (d with morning PEFR $\geqslant 20 \%$ below baseline, use of rescue medication $\geqslant 2 \mathrm{~d}$ above baseline, or nocturnal awakening by asthma).

\section{Main results}

Analysis was by intention to treat. Among group A patients, budesonide, $100 \mu \mathrm{g}$ twice daily, reduced the risk for a first severe asthma exacerbation (relative risk [RR] $0.40,95 \%$ CI 0.27 to 0.59 ) and the rate of poorly controlled asthma days (RR 0.52, CI 0.40 to 0.67 ) more than did placebo. Adding formoterol to budesonide did not affect these 2 outcomes.

Among group B patients, budesonide, $100 \mu \mathrm{g}$ and 200 $\mu \mathrm{g}$ twice daily, did not differ for risk for a first severe exacerbation or for rate of poorly controlled asthma days. Adding formoterol to budesonide, $100 \mu \mathrm{g}$ or $200 \mu \mathrm{g}$, reduced the risk for a first asthma exacerbation (RR 0.57 , CI 0.46 to 0.72 ) and the rate of poorly controlled asthma days (RR 0.70, CI 0.60 to 0.82). Budesonide, $100 \mu \mathrm{g}$, plus formoterol twice daily was more effective than budesonide, $200 \mu \mathrm{g}$ twice daily, for reducing the risk for a severe exacerbation day (RR 0.71 , CI 0.52 to 0.96 ) or a poorly controlled asthma day (RR 0.81, CI 0.66 to 0.99 ).

\section{Conclusions}

In corticosteroid free patients with mild asthma, budesonide, $100 \mu \mathrm{g}$ twice daily, reduced severe exacerbations and poorly controlled asthma days; the addition of formoterol conferred no added benefit. In patients already receiving inhaled corticosteroids, adding formoterol to budesonide, $100 \mu \mathrm{g}$ twice daily, was better than doubling the dose of budesonide.

*See glossary.

$\dagger$ Information provided by author. 